\title{
ANALISIS JAM KERJA EFEKTIF DALAM UPAYA PENINGKATAN PRODUKTIVITAS TENAGA KERJA DENGAN METODE PDCA DI PT NMI
}

\author{
Hery Hamdi Azwir, Heru Satriawan \\ Program Studi Teknik Industri, President University \\ Jl. Ki Hajar Dewantara Kota Jababeka, Cikarang, Bekasi \\ hery.azwir@president.ac.id, heru_satriawan@yahoo.com
}

\begin{abstract}
Abstrak
Adanya persaingan yang sangat ketat di pasar menuntut produsen untuk melakukan perbaikan secara terus menerus untuk menghasilkan produk dengan kualitas terbaik dan harga paling kompetitif. Hal tersebut merupakan suatu kewajiban yang tidak terhindarkan agar perusahaan mampu bertahan. PT NMI adalah produsen pedestal yang menganut sistem job order. Dalam usaha untuk meningkatkan daya saing karena meningkatnya tuntutan pelanggan, perusahaan ini memiliki kendala yang berkaitan dengan ketepatan waktu pengiriman. Hasil observasi yang dilakukan menunjukkan bahwa penyebabnya adalah utilisasi jam kerja yang masih rendah yaitu hanya 68,7\%. Penelitian ini bertujuan untuk mencari cara agar utilisasi dapat ditingkatkan sehingga kepastian waktu pengiriman menjadi lebih baik. Metodologi yang digunakan adalah analisis jam kerja efektif pada PT. NMI dengan menggunakan metode Plan-DoCheck-Act (PDCA). Pendekatan dilakukan dengan mengidentifikasi cara menaikkan utilisasi jam kerja agar dapat meningkatkan kapasitas produksi pedestal dengan memperhatikan produktivitas dan jumlah karyawan sehingga dapat memenuhi permintaan pelanggan dengan tepat waktu. Penerapan PDCA menghasilkan solusi bahwa upaya meningkatkan jam kerja efektif dapat dilakukan dengan merubah standard raw material yang digunakan dan standard kerja produksi. Setelah dilakukan perubahan standard raw material dan penggunaan standard kerja produksi yang baru, diperoleh hasil pemakaian jam kerja mengalami peningkatan dari $68,7 \%$ menjadi $82,4 \%$ dan produktivitas tenaga kerja meningkat dari 41 pcs/jam menjadi 52 pcs/jam.
\end{abstract}

Kata kunci : Kualitas, produktivitas, material, PDCA, utilisasi

\section{PENDAHULUAN}

PT. NMI merupakan perusahaan manufaktur yang menghasilkan produk pedestal dengan menganut sistim job order dimana hasil produksinya harus dijual sepasang dengan floor yang merupakan produk dari perusahaan lain. Kedua perusahaan ini saling bergantung dan sangat dituntut agar dapat memenuhi permintaan dengan tepat waktu. Untuk mengantisipasi permintaan yang terus meningkat, perusahaan perlu mencari cara yang efisien dan efektif untuk meningkatkan kapasitas produksinya. Dari hasil observasi, didapatkan data bahwa ternyata utilisasi tenaga kerja masih rendah yaitu rata-rata $68,7 \%$ dalam satu tahun. Utilisasi yang rendah ini tentu saja merugikan perusahaan dan membuka peluang untuk meningkatkan kapasitas produksi melalui peningkatan produktifitas tenaga kerja.

Pedestal (access floor) merupakan alat penyangga lantai yang dimaksudkan untuk membuat ruang kecil dibawah lantai tempat instalasi kabel dan kelistrikan. Produk ini umumnya digunakan pada gedung-gedung bertingkat dan perkantoran. Gambar 1, memperlihatkan pedestal, penggunaan, dan instalasinya. Pedestal terbagi menjadi dua bagian utama yaitu bagian atas yang di sebut Head Plate (H/P) dan bagian bawah disebut Base Plate (B/P). Dalam proses pembuatan, keduanya di assembly menjadi satu dengan menambahkan screw sebagai pengikat dan cushion rubber sebagai bantalan. Gambar 2 memperlihatkan proses instalasi pedestal. Penelitian ini bertujuan mencari cara untuk menaikkan utilisasi jam kerja agar dapat meningkatkan kapasitas produksi pedestal dengan memperhatikan produktivitas dan jumlah karyawan sehingga dapat memenuhi permintaan pelanggan dengan tepat waktu. 


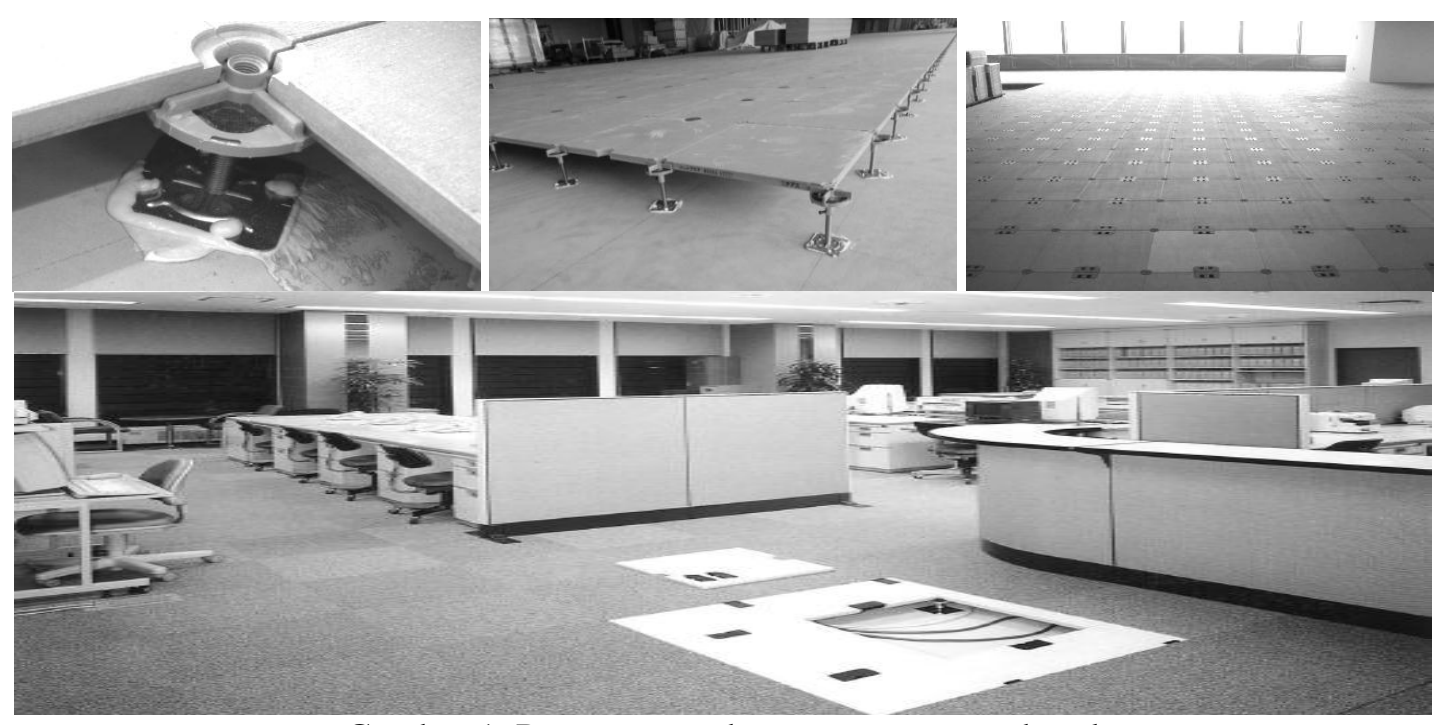

Gambar 1. Pemasangan dan penggunaan pedestal

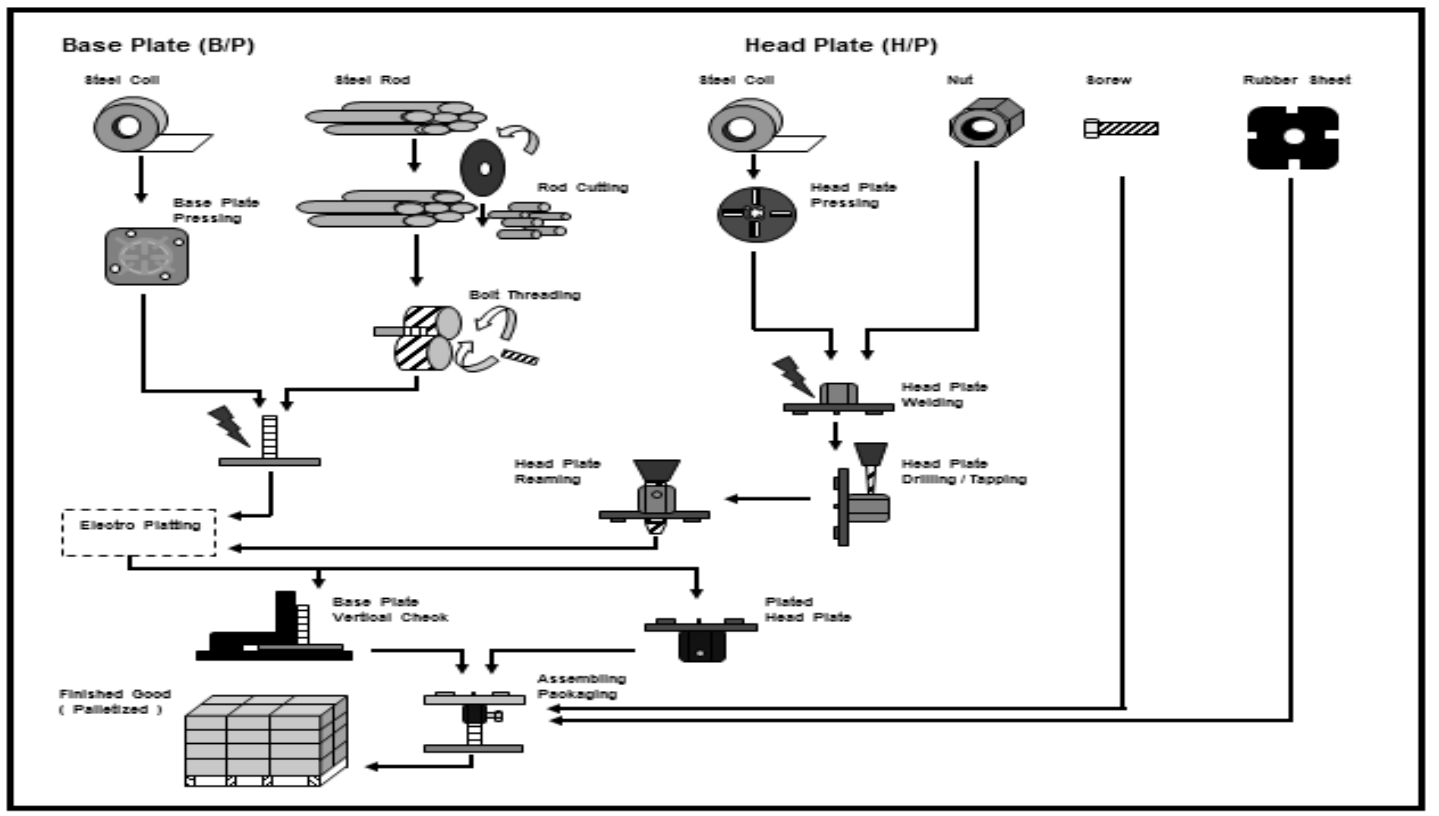

Gambar 2. Proses instalasi pedestal

\section{LANDASAN TEORI}

\section{A. TQM}

Total Quality Management (TQM) pada dasarnya merupakan konsep pengaplikasian sistem kualitas secara menyeluruh dalam organisasi mulai dari perencanaan, proses dan aktivitas yang menuntut partisipasi menyeluruh setiap individu dalam organisasi serta dukungan dan komitmen penuh dari jajaran petinggi dalam organisasi. Konsep awal pengembangan TQM dilatar belakangi kesuksesan revolusi industri di Jepang yang di prakarsai oleh W. Edwards Deming, yang kemudian dikenal sebagai bapak TQM. Deming membangun dan mengembangkan sistem yang dikenal dengan Statistical Process Control (SPC) yang membantu perusahaan dalam pengembangan kontrol kualitas yang pada perkembangannya lebih dikenal dengan istilah Deming Cycle (Siklus Deming). Model ini terdiri dari empat komponen utama yang berurutan yaitu Plan, Do, Check, Action (PDCA). 


\section{B. Produktivitas}

Di dalam ilmu ekonomi, produktivitas merupakan perbandingan antara hasil kegiatan (output, keluaran) dan segala pengorbanan (biaya) untuk mewujudkan hasil tersebut (input, masukan). Produktivitas sebagai pencapaian tujuan pada tingkat kualitas tertentu (output) dan efesiensi penggunaan sumber daya (input), sehingga produktivitas harus dikaitkan dengan aspek kualitas, efektifitas, dan efisiensi. [1]

Secara umum, produktivitas merupakan efisiensi penggunaan sumber daya untuk menghasilkan keluaran. Produktivitas adalah fungsi dari efisiensi dan efektivitas. Sehingga kegiatan yang dilakukan secara efisien dan efektif di dalam penggunaan sumber daya termasuk bahan, uang dan waktu sehingga menghasilkan produktivitas yang lebih tinggi. Dalam hal ini produktivitas tenaga kerja secara spesifik yang dimaksudkan adalah perbandingan antara hasil yang dicapai dengan peran serta kerja per satuan waktu. Sedangkan produktivitas perusahaan merupakan kumpulan dari produktivitas individu sehingga diperlukan perbaikan yang seimbang antara aspek manusia dan teknik. Peningkatan produktivitas perusahaan dapat dilakukan dengan langkah sebagai berikut [2]: (1) Menganalisis keadaan lebih dalam; (2) Merancang program peningkatan produktivitas; (3) Menciptakan kesadaran produktivitas; (4) Implementasi program peningkatan produktivitas; (5) Mengevaluasi program peningkatan produktivitas.

\section{Metode Plan, Do, Check, Action (PDCA)}

Metode W. Edwards Deming yang dikenal dengan Siklus Deming menyatakan bahwa setiap orang harus membuat rencana, mengumpulkan data menganalisisnya dan menyusun pekerjaan serta mempertahankan perputaran siklus tersebut yang merupakan cara untuk mempertahankan kualitas di dalam perusahaan. [3]

Setiap kegiatan dalam organisasi harus dituangkan dalam rencana kegiatan, kemudian rencana kegiatan tersebut dijalankan dan dimonitoring selama proses pelaksanaannya, selanjutnya dilakukan pengukuran dan penilaian terhadap hasil pelaksanaan kegiatan tersebut serta dilakukan analisis. Hasil analisis dapat digunakan sebagai acuan dalam perencanaan pengembangan selanjutnya.

Deming menekankan bahwa organisasi dapat mencapai perbaikan kualitas total (Total Quality Improvement), jika siklus PDCA terus berjalan. Siklus Deming dapat dilihat dalam gambar 3.

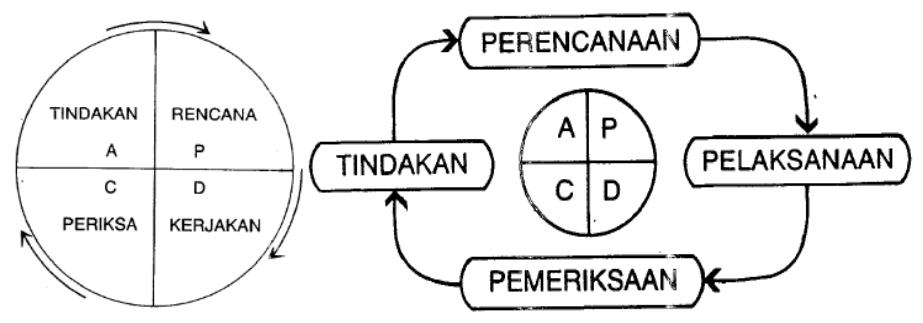

Gambar 3. Siklus dalam PDCA

\section{Plan (P)}

Plan merupakan tahap identifikasi "apa" yang harus dilakukan (WHAT) dan bagaimana melakukannya (HOW) dengan menggunakan beberapa alat bantu (Management Tools). [4]. Tahap ini meliputi 4 langkah yaitu: (1) Menentukan pokok persoalan (dapat mengacu pada konsep QCDSMEP atau quality, cost, delivery, safety, morale, productivity, dan environment); (2) Analisis akar masalah menggunakan fishbone diagram dimana faktor penyebab masalah dapat diklasifikasikan menjadi 5 atau sering disebut 4M1E yaitu Man, Machine, Methode, Material dan Environment.[5]; (3) Menguji atau menentukan penyebab utama dengan menggunakan metode $5 \mathrm{~W} 2 \mathrm{H}$ yaitu: what, why, where, how, when, who, how much; (4) Menyusun rencana penanggulangan dengan memperhatikan kriteria effect, technical, economic [1]. 


\begin{abstract}
Do (D)
Pada tahap ini, rencana yang disusun mulai dilaksanakan untukmenanggulangi penyebab masalahsesuaidenganrencanayangtelahditentukan. Tindakan diarahkan pada melaksanakan strategi, kebijakan, dan proses-proses yang diperlukan untuk mencapai hasil yang telah ditetapkan dalam sasaran mutu atau sesuai persyaratan pengguna.
\end{abstract}

\title{
Check (C)
}

Pada tahap ini, reviu dilakukan terhadap langkah yang sudah ditempuh, periksa apakah hasil yang terjadi sesuai dengan harapan? Lakukan perbandingan kondisi sebelum dan sesudah. Pada tahap ini, diperlukan pula analisis seberapa efektif percobaan yang telah dilakukan pada tahap sebelumnya.

\section{Action (A)}

Pada tahap ini, ambil tindakan berdasarkan apa yang kita pelajari pada langkah sebelumnya. Jika masih belum ada perubahan, ulangi dari awal siklusnya dengan cara yang berbeda. Tahap ini meliputi 2 langkah yaitu : Standardisasi dan Memilih persoalan berikutnya.

\section{Alat Bantu Dalam Langkah PDCA}

Pengembangan kontrol kualitas dalam implementasinya biasanya dibantu dengan beberapa alat bantu. Pemilihan alat bantu yang tepat pada tiap proses akan menghasilkan hasil yang optimal. Ada 7 (tujuh) alat bantu yang familiar dalam implementasi kontrol kualitas di perusahaan, yang biasa disebut $Q C 7$ Tools [6].

\section{E. Penelitian Metode PDCA}

Moen dan Norman [7] dalam artikelnya menyatakan bahwa PDCA dapat diterapkan dalam berbagai jenis organisasi danpada semua level. Siklus PDCA memberikan kerangka untuk aplikasi metode-metode perbaikan. Menyediakan cara yang sederhana bagi setiap orang untuk meimplementasikan perbaikan dan mendukung timkerja dalam proses implementasinya. Dubickis dan Gaile-Sarkane dalam artikelnya [8] menjelaskan juga bagaimana metode PDCA dikembangkan menjadi PDSA yang dapat membantu mempercepat proses transfer teknologi atau transfer pengetahuan dalam ruang lingkup inovasi terbuka (open innovation). Untuk itu ia mengusulkan enam langkah untuk proses belajar dan perbaikan. Pemanfaatan metode PDCA dalam lean manufacturing juga dilakukan dalam [9]

\section{METODOLOGI PENELITIAN}

Penelitian ini dikerjakan melalui sejumlah tahapan. Pada tahap awal, pengamatan dilakukan terhadap proses produksi pedestal (access floor) dan proses instalasinya. Dalam tahapan ini didapatkan bahwa perusahaan menganut sistem job order dan produk akhir sebenarnya adalah gabungan produk dari dua perusahaan berbeda yang mana perusahaan tersebut memproduksi bagian floornya. Setelah memahami proses produksi dan instalasi, berikutnya adalah mengumpulkan data yang terkait dengan utilisasi tenaga kerja dan pengukuran produktifitas untuk masing-masing proses. Berikutnya dilakukan analisis sebab akibat untuk mencari faktor yang paling berpengaruh atau berdampak dan akar masalah yang harus dibenahi. Setelah akar masalah diketahui maka dibuat rencana tindakan perbaikan untuk setiap faktor (Plan). Setelah rencana tindakan disusun dengan baik maka dilanjutkan denga pelaksanaan (Do) dengan menggunakan konsep 5W2H yaitu What, Why, Where, When, How, dan How Much. Setelah uji coba dilakukan maka dilakukan evaluasi (Check) untuk melihat dampak yang terjadi melalui pengumpulan data setelah perbaikan berupa data utilisasi jam kerja dan produktifitas. Setelah dapat dipastikan bahwa implementasi perbaikan yang dilakukan berdampak positif maka selanjutnya dilakukan standardisasi (Act). 


\section{HASIL DAN PEMBAHASAN}

\section{A. Plan}

Tahap ini terdiri dari empat langkah yaitu: identifikasi masalah, analisis sebab akibat, faktor paling berpengaruh dan perencanaan tindakan perbaikan.

\section{Identifikasi masalah}

Untuk dapat melakukan identifikasi masalah maka hal pertama yang harus dilakukan yaitu memahami proses produksi dan mengumpulkan data produksi pada periode tertentu. Tabel 1 adalah realisasi proses produksi Pedestal pada periode penelitian dilakukan di PT NMI. Dari tabel ini dapat diamati bahwa dari keseluruhan tahapan produksi, proses no. 1 (H/P dan B/P) ternyata memberikan realisasi produksi yang paling sedikit dengan selisih yang cukup besar dibandingkan dengan tahapan yang lain. Selain itu juga memiliki selisih yang cukup besar dibandingkan target perusahaan yaitu 24.800 pcs/hari. Sedangkan Tabel 2 menunjukkan utilisasi jam kerja karyawan yang masih rendah secara rata-rata adalah $68,7 \%$.

Tabel 1. Realisasi Proses Produksi Pedestal

\begin{tabular}{|c|c|c|c|c|c|c|c|c|}
\hline No & $\begin{array}{c}\text { Proses } \\
\text { Head Plate }\end{array}$ & $\begin{array}{c}\text { Jumlah } \\
\text { Mesin }\end{array}$ & $\begin{array}{l}\text { Produktivitas } \\
\text { (pcs/jam) }\end{array}$ & $\begin{array}{l}\text { Realisasi } \\
\text { (pcs/hari) }\end{array}$ & $\begin{array}{l}\text { Realisasi } \\
\text { (pcs/hari) }\end{array}$ & $\begin{array}{l}\text { Produktivitas } \\
\text { (pcs/jam) }\end{array}$ & $\begin{array}{l}\text { Jumlah } \\
\text { Mesin }\end{array}$ & $\begin{array}{c}\text { Proses } \\
\text { Base Plate }\end{array}$ \\
\hline \multirow{2}{*}{1} & \multirow{2}{*}{$\begin{array}{l}\text { H/P Press } \\
\text { Auto }\end{array}$} & \multirow{2}{*}{1} & \multirow{2}{*}{2.808} & \multirow{2}{*}{21.537} & \multirow{2}{*}{22.078} & 661 & 1 & $\begin{array}{l}\text { B/P Press } \\
\text { Manual }\end{array}$ \\
\hline & & & & & & 2.548 & 1 & $\begin{array}{ll}\text { B/P Press } \\
\text { Auto }\end{array}$ \\
\hline 2 & $\begin{array}{l}\text { Drill, \& } \\
\text { Tap Man }\end{array}$ & 1 & 527 & \multirow{2}{*}{27.236} & \multirow{2}{*}{30.250} & \multirow[b]{2}{*}{986} & \multirow{2}{*}{4} & \multirow{2}{*}{$\begin{array}{l}\text { Cutting } \\
\text { Rod }\end{array}$} \\
\hline 3 & $\begin{array}{l}\text { Drill \& } \\
\text { Tap Auto }\end{array}$ & 4 & 756 & & & & & \\
\hline 4 & Reaming & 4 & 985 & 30.220 & 33.656 & 1.097 & 4 & Threading \\
\hline \multirow{2}{*}{5} & \multirow{2}{*}{$\begin{array}{l}\text { H/P } \\
\text { Projection }\end{array}$} & \multirow{2}{*}{4} & \multirow{2}{*}{929} & \multirow{2}{*}{28.502} & \multirow{2}{*}{27.474} & 797 & 4 & B/P Proj \\
\hline & & & & & & 197 & 2 & B/P Co2 \\
\hline 6 & $\begin{array}{l}\text { H/P } \\
\text { Plating }\end{array}$ & 1 & 3.600 & 27.612 & 27.612 & 3.600 & 1 & $\begin{array}{l}\text { B/P } \\
\text { Plating }\end{array}$ \\
\hline 7 & Assembly & 12 & 268 & & & 268 & 12 & Assembly \\
\hline
\end{tabular}

Tabel 2. Utilisasi Jam Kerja

\begin{tabular}{|l|l|l|l|l|l|l|l|l|l|l|l|}
\hline $\begin{array}{l}\text { Jam } \\
\text { Kerja }\end{array}$ & Satuan & Jan & Feb & Mar & Apr & Mei & Jun & Jul & Agust & Sept & Total \\
\hline Tersedia & Jam & 9.442 & 8.673 & 7.241 & 5.745 & 7.507 & 8.007 & 6.459 & 8.698 & 7.850 & 69.622 \\
\hline Terpakai & Jam & 7.194 & 6.064 & 5.105 & 3.514 & 4.908 & 5.304 & 4.097 & 6.098 & 5.559 & 47.843 \\
\hline Utilisasi & $\%$ & $76,2 \%$ & $69,9 \%$ & $70,5 \%$ & $61,2 \%$ & $65,4 \%$ & $66,2 \%$ & $63,4 \%$ & $70,1 \%$ & $70,8 \%$ & $68,7 \%$ \\
\hline
\end{tabular}

\section{Analisis sebab akibat}

Berdasarkan Tabel 1 dan 2 dapat diidentifikasi masalah dari masih rendahnya utilisasi jam kerja berkaitan erat dengan kapasitas produksi pedestal pada masing-masing proses yang berbeda-beda. Kapasitas terendah berada pada proses awal. Dapat dilihat pada pembuatan head plate kapasitas terendah ada pada proses H/P press auto yaitu sebesar 21.537 pcs/hari. Sedangkan untuk pembuatan base plate kapasitas terendah terdapat pada proses $B / P$ press auto dan manual sebesar 22.078 pcs/hari. Kapasitas produksi pada proses $H / P$ press dan $B / P$ press masih dibawah target standard perusahaan yaitu sebesar $24.800 \mathrm{pcs} / \mathrm{hari}$. Mengacu pada keadaan tersebut dibuat diagram fishbone untuk mencari akar masalah, apa penyebab rendahnya produktivitas pada proses press head plate dan base plate. Gambar 4 memperlihatkan diagram fishbone untuk mencari akar masalah yang dilihat dari beberapa faktor yaitu 4M1E (Methode, 
Man, Machine, Material dan Environtment).

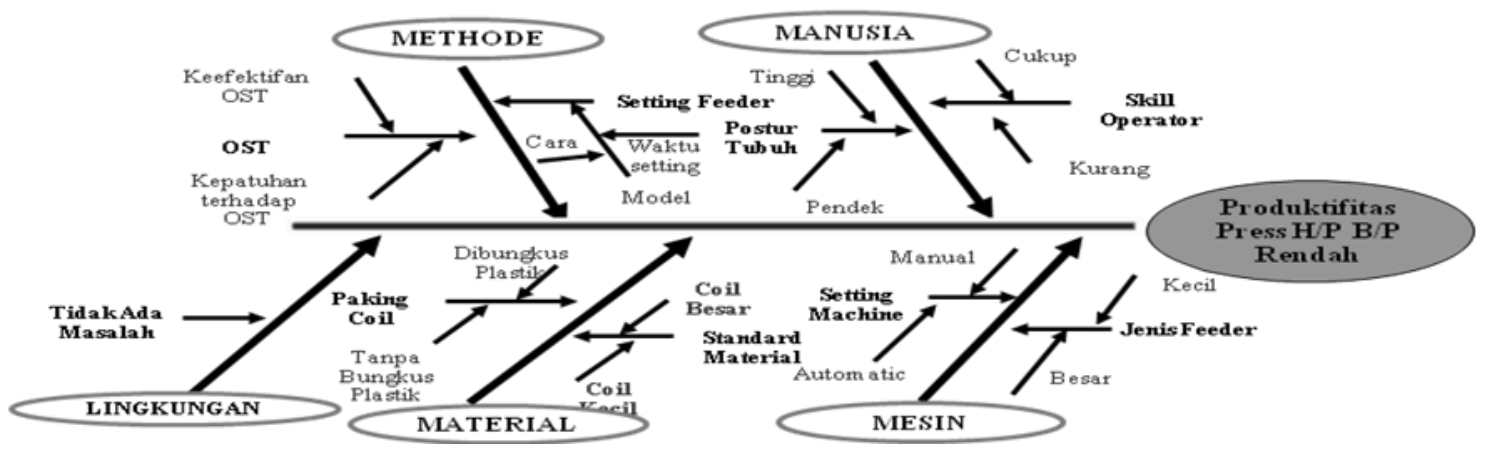

Gambar 4. Fishbone diagram pada Proses Press

\section{Mencari faktor paling berpengaruh}

Langkah yang ke tiga yaitu mencari faktor paling berpengaruh. Untuk mengetahui penyebab masalah utama maka dibuat scoring dengan menggunakan aspek Quality, Cost, Delivery, Safety, Mental, Environment \& Productivity (QCDSMEP) dengan mengacu dari diagram sebab akibat (fishbone) sebagaimana diperlihatkan dalam tabel 3.

Tabel 3. Tingkat pengaruh akar masalah fishbone diagram

\begin{tabular}{|c|c|c|c|c|c|c|c|c|c|c|c|c|}
\hline \multirow{2}{*}{ No } & \multirow{2}{*}{ Faktor } & \multirow{2}{*}{$\begin{array}{c}\text { Akar Masalah } \\
\text { (Penyebab) }\end{array}$} & \multicolumn{7}{|c|}{ ASPECT } & \multirow{2}{*}{ Total } & \multirow{2}{*}{$\%$} & \multirow{2}{*}{ Urutan } \\
\hline & & & $\mathbf{Q}$ & $\mathrm{C}$ & D & $\mathbf{S}$ & $\mathbf{M}$ & $\mathbf{E}$ & $\mathbf{P}$ & & & \\
\hline \multirow{2}{*}{1} & \multirow{2}{*}{ Manusia } & Skill operator & 1 & 0 & 0 & 1 & 1 & 0 & 1 & 4 & $16.7 \%$ & 2 \\
\hline & & Postur tubuh operator & 1 & 0 & 0 & 1 & 0 & 0 & 0 & 2 & $8.3 \%$ & 8 \\
\hline \multirow{2}{*}{2} & \multirow{2}{*}{ Metode } & Keefektifan OST & 1 & 0 & 0 & 1 & 0 & 0 & 1 & 3 & $12.9 \%$ & 4 \\
\hline & & Setting mesin feeder & 0 & 0 & 0 & 1 & 0 & 0 & 1 & 2 & $8.3 \%$ & 7 \\
\hline \multirow{2}{*}{3} & \multirow{2}{*}{ Mesin } & Type Mesin & 0 & 0 & 1 & 1 & 0 & 0 & 1 & 3 & $12.9 \%$ & 3 \\
\hline & & Setting mesin & 1 & 0 & 0 & 1 & 0 & 0 & 0 & 2 & $8.3 \%$ & 6 \\
\hline \multirow{2}{*}{4} & \multirow{2}{*}{ Material } & Standard material & 1 & 1 & 1 & 1 & 0 & 0 & 1 & 5 & $20.8 \%$ & 1 \\
\hline & & Paking material & 0 & 0 & 0 & 1 & 0 & 1 & 1 & 3 & $12.9 \%$ & 5 \\
\hline 5 & Lingkungan & Tempat kerja & 0 & 0 & 0 & 0 & 0 & 0 & 0 & 0 & $0.0 \%$ & 9 \\
\hline
\end{tabular}

Selanjutnya dibuat Pareto diagram sebagimana ditunjukkan dalam Gambar 5.

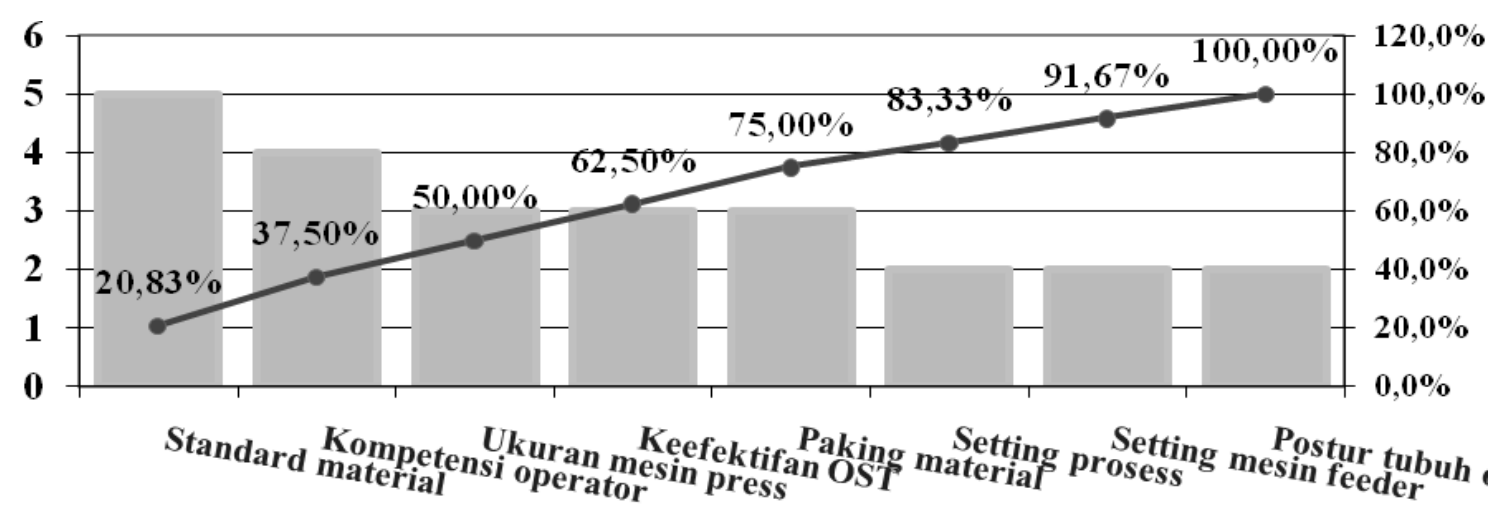

Gambar 5. Pareto diagram penyebab utama 


\section{MerencanakanTindakan Perbaikan}

Langkah yang ke empat yaitu membuat rencana tindakan perbaikan. Untuk memudahkan implementasi tindakan maka pembahasan dikelompokkan sesuai dengan masing-masing faktor berdasarkan diagram fishbone pada gambar 4.

\section{Faktor Material}

Dapat diketahui bahwa penyebab tertinggi produktivitas head plate dan base plate press rendah yaitu standard material yang digunakan dan cara paking coil. Masih rendahnya produktivitas pada kategori material disebabkan steel plate coil yang digunakan saat ini menggunakan ukuran yang kecil sehingga penggantian material sering dilakukan dimana waktu yang dibutuhkan untuk penggantian material mencapai 12 menit, sehingga perlu dievaluasi standard berat material yang digunakan dengan memperhatikan dari kapasitas mesin pres.

\section{Faktor Manusia}

Dapat dilihat bahwa penyebab produktivitas head plate dan base plate press rendah yaitu skill operator dan postur tubuh operator. Masih rendahnya produktivitas pada kategori manusia adalah masih terdapat operator yang belum mahir mengoperasikan mesin yang berbeda sehingga perlu dilakukan trainning bagi seluruh operator untuk meningkatkan kompetensi yang dimiliki.

\section{Faktor Metode}

Dari gambar 4 dapat diketahui bahwa penyebab produktivitas $H / P$ dan $B / P$ press rendah yaitu setting feeder dan OST belum efektif. Masih rendahnya produktivitas pada kategori metode yaitu tingkat kepatuhan operator terhadap OST. Didalam pelaksanaan masih dijumpai operator bekerja tanpa mematuhi $O S T$, namun hanya berdasarkan kebiasaan, perlu direview OST focus pada kemudahan proses dan keselamatan.

\section{Faktor Mesin}

Dari fishbone diagram Gambar 4 dapat diketahui bahwa penyebab produktivitas proses $H / P$ dan $B / P$ press rendah yaitu jenis mesin dan setting mesin. Masih rendahnya produktivitas proses pres pada kategori mesin disebabkan kemampuan operator. Mesin press terdapat 2 model mesin yaitu auto dan manual sehingga operator dituntut untuk mampu mengoperasikan ke dua model mesin tersebut dengan benar.

\section{B. Do}

Tahap yang kedua dalam PDCA yaitu do yang berarti melaksanakan tindakan perbaikan. Pada tahap ini, setelah faktor-faktor dominan diketahui, maka mulai dilakukan tindakan perbaikan guna penanggulangan masalah yang ada. Tindakan diarahkan pada pelaksanaan strategi, kebijakan, dan proses-proses yang diperlukan untuk mencapai hasil yang telah ditetapkan dalam sasaran mutu. Dalam pelaksanaan tindakan perbaikan tersebut menggunakan dasar 5W2H yaitu What, Why, Where, When, How dan How Much, seperti pada terlihat pada Tabel 4. 
Tabel 4. Langkah-langkah tindakan perbaikan

\begin{tabular}{|c|c|c|c|c|c|c|c|c|c|}
\hline \multirow{2}{*}{$\underset{0}{0}$} & \multirow{2}{*}{$\sum_{i=1}^{\sharp}$} & \multicolumn{2}{|c|}{ WHAT } & \multirow{2}{*}{$\begin{array}{l}\text { WHY } \\
\text { Alasan }\end{array}$} & \multirow{2}{*}{$\begin{array}{c}\text { HOW } \\
\text { Bagaimana }\end{array}$} & \multirow{2}{*}{ Tempat } & \multirow{2}{*}{$\sum_{\text {Kapan }}^{Z}$} & \multirow{2}{*}{ PIC } & \multirow{2}{*}{ Biaya } \\
\hline & & Penyebab & Effect & & & & & & \\
\hline Mesin & $\begin{array}{l}\text { Type } \\
\text { mesin press }\end{array}$ & $\begin{array}{l}\text { Proses } \\
\text { Press ada } 2 \\
\text { macam : } \\
\text { manual dan } \\
\text { automatic }\end{array}$ & $\begin{array}{l}\text { Kecepatan } \\
\text { proses } \\
\text { berbeda } \\
\text { antara manual } \\
\text { dan otomatis }\end{array}$ & $\begin{array}{l}\text { Productivity } \\
\text { manual lebih } \\
\text { rendah } \\
\text { dibanding } \\
\text { dengan yang } \\
\text { otomatis } \\
\end{array}$ & $\begin{array}{l}\text { Modifikasi } \\
\text { menjadi proses } \\
\text { otomatis }\end{array}$ & $\begin{array}{l}\text { Mesin } \\
\text { Press }\end{array}$ & Des 15 & MTC & $\mathrm{X}$ \\
\hline Metode & $\begin{array}{l}\text { Keefektifan } \\
\text { OST }\end{array}$ & $\begin{array}{l}\text { Tidak } \\
\text { semua } \\
\text { operator } \\
\text { patuh } \\
\text { terhadap } \\
\text { prosedure } \\
\text { kerja (OST) }\end{array}$ & $\begin{array}{l}\text { Lamanya } \\
\text { waktu setting } \\
\text { berbeda-beda } \\
\text { tergantung } \\
\text { cara operator }\end{array}$ & $\begin{array}{l}\text { Operator } \\
\text { menganggap } \\
\text { bahwa cara } \\
\text { setting mereka } \\
\text { paling nyaman }\end{array}$ & $\begin{array}{l}\text { Review OST dan } \\
\text { hasil review } \\
\text { disosialisasikan } \\
\text { ke operator dan } \\
\text { dipasang }\end{array}$ & $\begin{array}{l}\text { Proses } \\
\text { Press }\end{array}$ & Des 15 & PDT & - \\
\hline Manusia & $\begin{array}{l}\text { Kompetensi } \\
\text { operator }\end{array}$ & $\begin{array}{l}\text { Kurangnya } \\
\text { motivasi } \\
\text { operator }\end{array}$ & $\begin{array}{l}\text { Mempengaruh } \\
\text { i kinerja } \\
\text { operator }\end{array}$ & $\begin{array}{l}\text { Kurang } \\
\text { tanggung } \\
\text { jawab dan } \\
\text { belum paham } \\
\text { akan efek } \\
\text { untuk proses } \\
\text { berikutnya } \\
\end{array}$ & $\begin{array}{l}\text { Breefing di area } \\
\text { kerja tentang } \\
\text { tanggung jawab } \\
\text { dan efek atas } \\
\text { pekerjaan yg } \\
\text { dilakukan. }\end{array}$ & $\begin{array}{l}\text { Proses } \\
\text { Press }\end{array}$ & Des 15 & PDT & - \\
\hline Material & $\begin{array}{l}\text { Standard } \\
\text { material }\end{array}$ & $\begin{array}{l}\text { Standard } \\
\text { material } \\
\text { kecil }\end{array}$ & $\begin{array}{l}\text { Pergantian } \\
\text { material di } \\
\text { mesin } \\
\text { menjadi } \\
\text { sering }\end{array}$ & $\begin{array}{l}\text { Material tidak } \\
\text { didasarkan } \\
\text { pada kapasitas } \\
\text { dari } \\
\text { kemampuan } \\
\text { mesin }\end{array}$ & $\begin{array}{l}\text { Evaluasi standard } \\
\text { material yang ada } \\
\text { menyesuaikan } \\
\text { dengan kapasitas } \\
\text { mesin }\end{array}$ & $\begin{array}{l}\text { Suplier } \\
\text { Coil }\end{array}$ & Des 15 & $\mathrm{PCH}$ & - \\
\hline
\end{tabular}

\section{Check}

Tahap yang ke tiga yaitu check. Adapun kegiatan yang dilakukan pada tahap ini yaitu memeriksa hasil dari perbaikan. Review dilakukan terhadap langkah yang sudah ditempuh, apakah hasil yang diperoleh sesuai dengan harapan. Langkah yang dilakukan yaitu membandingkan kondisi sebelum dan sesudah dilakukan perbaikan. Sehingga dapat diperoleh analisis keefektifitasan perbaikan yang sudah dilakukan. Setelah dilakukan perbaikan dengan melihat pada faktor manusia, mesin, material dan metode maka diperoleh hasil peningkatan produktivitas pada proses Head Plate dan Base Plate press seperti terdapat pada gambar 6 dan tabel 5.

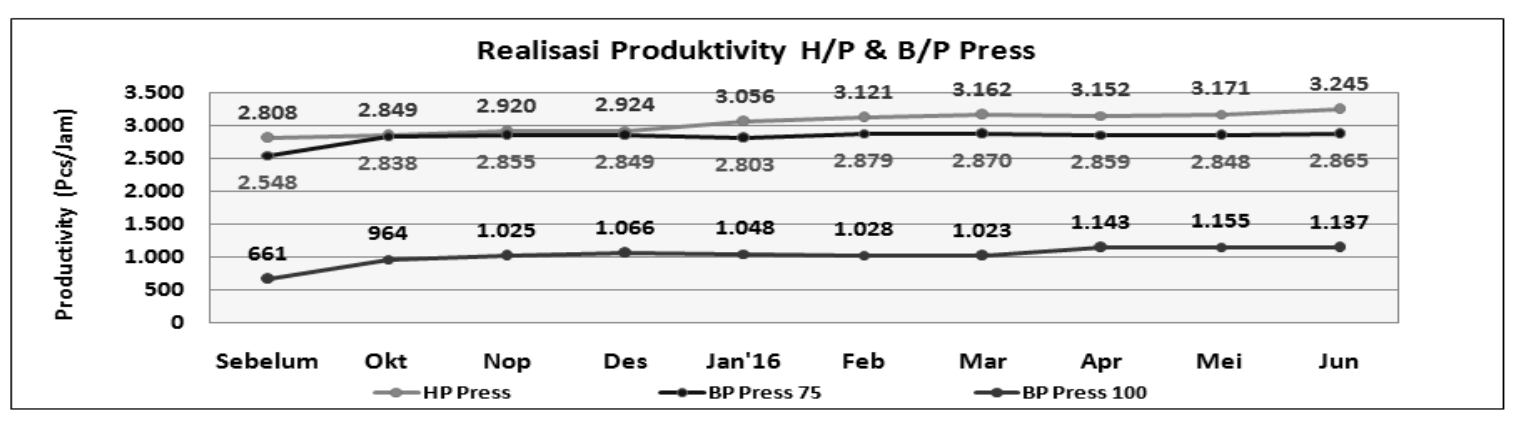

Gambar 6. Realisasi produktivitas $H / P \& B / P$ press 
Tabel 5. Produktivitas Head Plate dan Base Plate Press

\begin{tabular}{|c|c|c|c|c|c|c|c|c|c|c|c|c|}
\hline Proses & Satuan & Sebelum & Okt & Nop & Des & Jan'16 & Feb & Mar & Apr & Mei & Jun & Avg \\
\hline $\begin{array}{c}\text { H/P } \\
\text { Press }\end{array}$ & Jam & $\mathbf{2 . 8 0 8}$ & 2.849 & 2.920 & 2.924 & 3.056 & 3.121 & 3.162 & 3.152 & 3.171 & 3.245 & $\mathbf{3 . 0 6 3}$ \\
\hline $\begin{array}{c}\text { B/P } \\
\text { Press 75 }\end{array}$ & Jam & $\mathbf{2 . 5 4 8}$ & 2.838 & 2.855 & 2.849 & 2.803 & 2.879 & 2.870 & 2.859 & 2.848 & 2.865 & $\mathbf{2 . 8 5 3}$ \\
\hline $\begin{array}{c}\text { B/P } \\
\text { Press100 }\end{array}$ & Jam & $\mathbf{6 6 1}$ & 964 & 1.025 & 1.066 & 1.048 & 1.028 & 1.023 & 1.143 & 1.155 & 1.137 & $\mathbf{1 . 0 7 7}$ \\
\hline
\end{tabular}

Dengan peningkatan produktivitas pada proses press menyebabkan peningkatan peningkatan jam kerja efektif sebagaimana ditunjukkan dalam gambar 7 dan tabel 6.

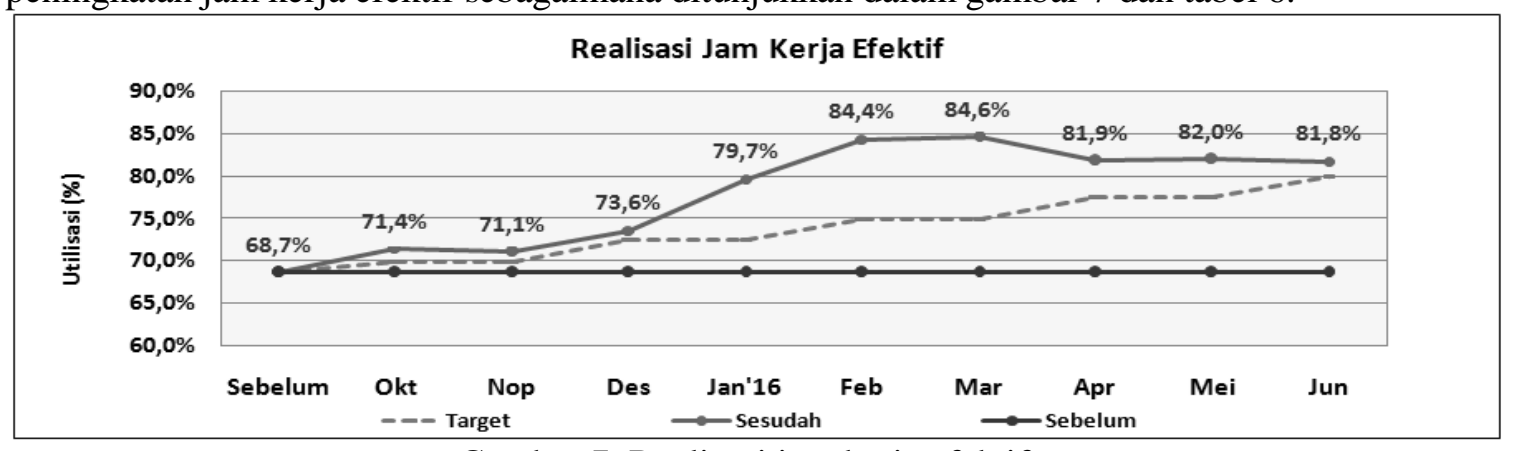

Gambar 7. Realisasi jam kerja efektif

Tabel 6. Jam Kerja Efektif Proses Pedestal

\begin{tabular}{|c|c|c|c|c|c|c|c|c|c|c|c|c|}
\hline $\begin{array}{c}\text { Jam } \\
\text { Kerja }\end{array}$ & Satuan & Sebelum & Okt & Nop & Des & Jan'16 & Feb & Mar & Apr & Mei & Jun & Avg \\
\hline $\begin{array}{c}\text { Jam } \\
\text { Tersedia }\end{array}$ & Jam & $\mathbf{7 . 7 3 6}$ & 9.155 & 10.101 & 10.782 & 11.036 & 9.887 & 9.746 & 8.349 & 8.754 & 8.623 & $\mathbf{9 . 6 0 4}$ \\
\hline $\begin{array}{c}\text { Jam } \\
\text { Terpakai }\end{array}$ & Jam & $\mathbf{5 . 3 1 6}$ & 6.534 & 7.180 & 7.937 & 8.797 & 8.344 & 8.244 & 6.836 & 7.178 & 7.058 & $\mathbf{7 . 5 6 8}$ \\
\hline $\begin{array}{c}\text { Jam } \\
\text { Efektif }\end{array}$ & $\%$ & $\mathbf{6 8 , 7}$ & 71,4 & 71,1 & 73,6 & 79,7 & 84,4 & 84,6 & 81,9 & 82,0 & 81,8 & $\mathbf{7 8 , 8}$ \\
\hline
\end{tabular}

Efek dari peningkatan produktivitas pada proses press berpengaruh pada peningkatan produktivitas tenaga kerja terlihat pada gambar 8 dan tabel 7.

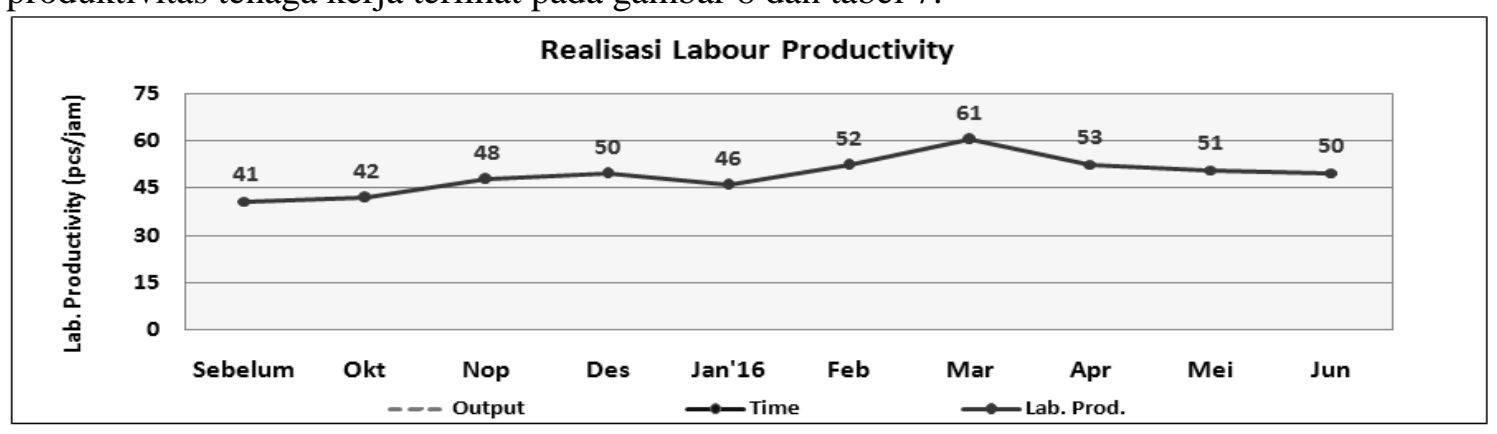

Gambar 8. Realisasi produktivitas tenaga kerja

Tabel 7. Hasil produktivitas tenaga kerja Pedestal

\begin{tabular}{|c|c|c|c|c|c|c|c|c|c|c|c|c|}
\hline Proses & Ea & Sebelum & Okt & Nop & Des & Jan'16 & Feb & Mar & Apr & Mei & Jun & AVG \\
\hline $\begin{array}{c}\text { Total } \\
\text { Produksi }\end{array}$ & Pcs & 315.970 & 385.266 & 484.840 & 536.426 & 509.094 & 518.148 & 589.920 & 439.434 & 444.772 & 430.864 & 482.085 \\
\hline $\begin{array}{c}\text { Labour } \\
\text { Prod }\end{array}$ & $\begin{array}{c}\text { Pcs } \\
\text { hr }\end{array}$ & 41 & 42 & 48 & 50 & 46 & 52 & 61 & 53 & 51 & 50 & 50 \\
\hline
\end{tabular}




\section{Action}

Langkah terakhir dalam PDCA adalah act (mengambil tindakan). Pada tahap ini terdapat dua kegiatan yaitu standardisasi dan melakukan perbaikan terhadap masalah yang lainnya. Berdasarkan dari hasil perbaikan yang telah didapat maka dilakukan standardisasi hal ini untuk mencegah terjadinya masalah lama terulang kembali dan mempertahankan peningkatan hasil yang sudah diperoleh. Dalam pelaksanaannya agar mempermudah langkah standarisasi proses maka dikelompokkan sesuai dengan masing-masing faktor :

1. Faktor Metode

Untuk mempermudah dalam memahami prosedur pengoperasian mesin pada proses press maka dilakukan perbaikan standar operasi.

2. Faktor Mesin

Dilakukan modifikasi mesin dengan pemasangan safety tool press multidetector sehingga proses auto dapat dilakukan untuk proses base plate press. Setelah dilakukan percobaan dan hasil produktivitas pada proses press $B / P$ (base plate) mengalami peningkatan maka diputuskan merubah material yang digunakan dari steel sheet menjadi steel coil.

3. Faktor Material

Setelah dilakukan trial dengan melakukan perubahan ukuran coil slitting menjadi lebih besar dan didapat peningkatan produktivitas pada proses press B/P (base plate) dan $H / P$ (head plate) maka untuk pembelian material selanjutnya dilakukan perubahan standard ukuran dari 11-13 M.ton menjadi ukuran 8-10 M.ton per coil ditulis pada sales contract pembelian.

4. Faktor Manusia

Setelah dilakukan dilakukan briefing, pengenalan dan trainning prosedur press baru dan trainning proses press sesuai OST yang baru berdasarkan hasil penilaian skill matrix operator press mengalami peningkatan kemampuan dibandingkan sebelumnya.

\section{E. Rangkuman}

Setelah dilakukan langkah perbaikan dengan menggunakan sistem PDCA (Plan-Do-CheckAct) dengan melihat pada faktor Man, Methode, Material, Machine dan Enviroment didapat hasil sebagaimana ditunjukkan dalam tabel 8.

Tabel 8. Peningkatan Produktivitas $H / P$ dan $B / P$ Press

\begin{tabular}{|c|c|c|c|c|}
\hline $\begin{array}{l}\mathrm{N} \\
\mathrm{o}\end{array}$ & $\begin{array}{l}\text { Proses } \\
\text { Head } \\
\text { Plate }\end{array}$ & $\begin{array}{l}\text { Jumlah } \\
\text { Mesin }\end{array}$ & $\begin{array}{l}\text { Productivitas } \\
\text { (pcs/jam) }\end{array}$ & $\begin{array}{l}\text { Realisasi } \\
\text { (pcs/hari) }\end{array}$ \\
\hline 1 & $\begin{array}{c}\text { H/P Press } \\
\text { Auto } \\
\text { Jan }- \text { Sept } \\
' 15\end{array}$ & 1 & 2.808 & 21.537 \\
\hline 2 & $\begin{array}{c}\text { H/P Press } \\
\text { Auto } \\
\text { Oct - Dec } \\
15\end{array}$ & 1 & 2.901 & 22.250 \\
\hline 3 & $\begin{array}{c}\text { H/P Press } \\
\text { Auto } \\
\text { Jan - Jun } \\
' 16\end{array}$ & 1 & 3.151 & 24.165 \\
\hline
\end{tabular}

\begin{tabular}{|c|c|c|c|}
\hline \multirow{2}{*}{$\begin{array}{c}\text { Realisasi } \\
\text { (pcs/hari) }\end{array}$} & $\begin{array}{c}\text { Productivitas } \\
\text { (pcs/jam) }\end{array}$ & $\begin{array}{c}\text { Jumlah } \\
\text { Mesin }\end{array}$ & $\begin{array}{c}\text { Proses } \\
\text { Base } \\
\text { Plate }\end{array}$ \\
\hline \hline \multirow{2}{*}{$\mathbf{2 2 . 0 7 8}$} & 661 & 1 & $\begin{array}{l}\text { B/P } \\
\text { Press } \\
\text { Manual }\end{array}$ \\
\cline { 2 - 4 } & 2.548 & 1 & $\begin{array}{l}\text { B/P } \\
\text { Press } \\
\text { Auto }\end{array}$ \\
\hline \hline \multirow{25.693}{*25}{} & 1.004 & 1 & $\begin{array}{l}\text { B/P } \\
\text { Press } \\
\text { Auto }\end{array}$ \\
\cline { 2 - 4 } & 2.848 & 1 & $\begin{array}{l}\text { B/P } \\
\text { Press } \\
\text { Auto }\end{array}$ \\
\hline \hline \multirow{2}{*}{$\mathbf{2 6 . 1 3 5}$} & 1.105 & 1 & $\begin{array}{l}\text { B/P } \\
\text { Press } \\
\text { Auto }\end{array}$ \\
\cline { 2 - 4 } & 2.855 & 1 & $\begin{array}{l}\text { B/P } \\
\text { Press } \\
\text { Auto }\end{array}$ \\
\hline
\end{tabular}


Benefit yang diperoleh dengan peningkatan produktivitas $H / P$ dan $B / P$ press pada proses pedestal seperti gambar 9.

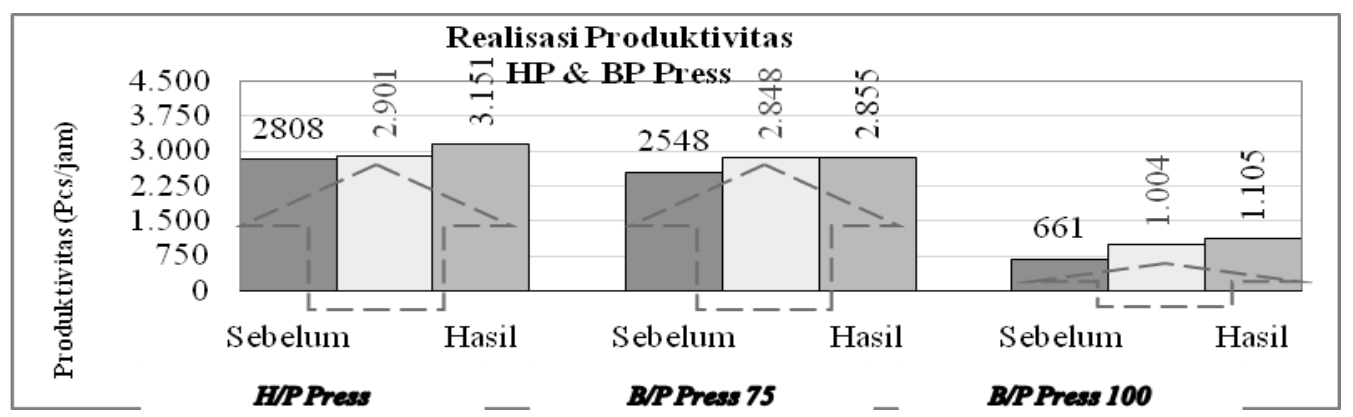

Gambar 9. Realisasi Produktivitas H/P dan B/P Press

Dengan peningkatan produktivitas $H / P$ dan $B / P$ press pada proses pedestal jam kerja efektif meningkat dari $68,7 \%$ menjadi $82,4 \%$ dan produktifitas tenaga kerja meningkat dari 41 pcs/jam menjadi 52\% seperti gambar 10 dan tabel 9.

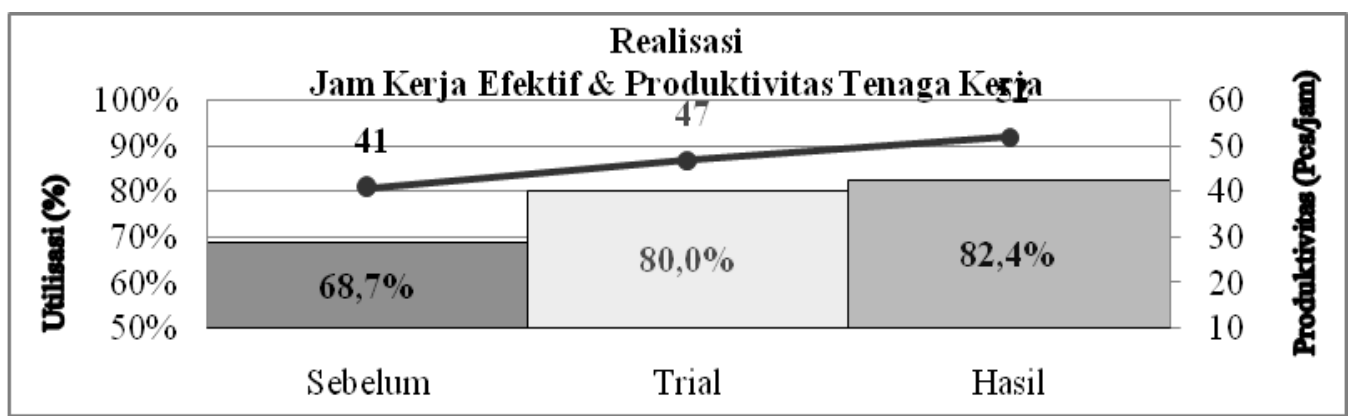

Gambar 10. Realisasi jam kerja efektif dan produktivitas tenaga kerja

Tabel 9. Hasil pencapaian produksi sebelum dan sesudah perbaikan

\begin{tabular}{|l|c|c|c|c|}
\hline \multicolumn{1}{|c|}{ Proses } & Satuan & Jan - Sept '15 & Okt - Des '15 & Jan-Jun '16 \\
\hline Prod. H/P Press & Pcs/Jam & 2.808 & 2.901 & 3.151 \\
\hline Prod. B/P Press 75 & Pcs/Jam & 2.548 & 2.848 & 2.855 \\
\hline Prod. B/P Press 100 & Pcs/Jam & 661 & 1.004 & 1.105 \\
\hline Prod. Tenaga Kerja & Pcs/Jam & 41 & 47 & 52 \\
\hline Jam Kerja Efektif & $\%$ & $68,7 \%$ & $72,1 \%$ & $82,4 \%$ \\
\hline
\end{tabular}

Berdasarkan tabel 9 dapat disimpulkan peningkatan produktivitas pada proses Head Plate dan Base Plate press berpengaruh pada peningkatan Jam kerja efektif dari 68,7\% menjadi $82,4 \%$, efek dari peningkatan tersebut produktivitas tenaga kerja mengalami peningkatan dari $41 \mathrm{pcs} / \mathrm{jam}$ menjadi $52 \mathrm{pcs} / \mathrm{jam}$. Dengan demikian kapasitas produksi mengalami peningkatan dari :

$=$ Produktivitas tenaga kerja $\mathrm{x}$ Jumlah jam kerja sehari $\mathrm{x}$ Jumlah tenaga kerja

$=41 \mathrm{pcs} / \mathrm{jam} \times 8 \mathrm{jam} / \mathrm{hari} \times 62$ orang $=20.336 \mathrm{pcs} / \mathrm{hari}$

Meningkat menjadi :

$=$ Produktivitas tenaga kerja $\mathrm{x}$ Jumlah jam kerja sehari $\mathrm{x}$ Jumlah tenaga kerja

$=52 \mathrm{pcs} / \mathrm{jam} \times 8 \mathrm{jam} / \mathrm{hari} \times 62$ orang $=25.792 \mathrm{pcs} / \mathrm{hari}$

Dari hasil tersebut kapasitas produksi pedestal mengalami peningkatan sebanyak 5.456 pcs/hari atau meningkat sebesar $26.83 \%$ 


\section{SIMPULAN DAN SARAN}

Penerapan metode PDCA dalam usaha menaikkan prosentase jam kerja efektif yang bertujuan meningkatkan pencapaian produktivitas tenaga kerja pada proses pedestal ternyata memberikan dampak positif. Hasil yang diperoleh yaitu jam kerja efektif meningkat dari $68,7 \%$ menjadi $82,4 \%$, dengan peningkatan tersebut, produktivitas tenaga kerja mengalami peningkatan sebanyak 11 pcs/jam dari 41 pcs/jam menjadi 52 pcs/jam. Dengan peningkatan tersebut maka kapasitas produksi Pedestal mengalami peningkatan menjadi 25.792 pcs/hari diatas dari target produksi harian sebanyak $24.800 \mathrm{pcs} / \mathrm{hari}$ atau meningkat sebanyak $26.83 \%$.

Disarankan usaha untuk menaikkan jam kerja efektif dalam rangka peningkatkan produktivitas tenaga kerja selanjutnya yaitu dengan penerapan konveyor antar proses. Dengan sistem konveyor operator tidak lagi memindahkan hasil produksinya secara manual. Sehingga mengurangi beban kerja operator sekaligus meminimalkan resiko cedera bagi operator. Untuk mencegah timbulnya masalah baru dalam setiap aktifitas perbaikan dalam metode PDCA maka keikutsertaan operator pada proses bersangkutan sangat dianjurkan karena kenyamanan dan keamanan dalam proses kegiatan merupakan pertimbangan utama.

\section{DAFTAR PUSTAKA}

[1] Gaspersz Vincent, 2011, Total Quality Management, Vinchristo Publication, Jakarta.

[2] Nasution Nur M., 2005, Manajemen Mutu Terpadu (Total Quality Management), Ghalia Indonesia, Jakarta.

[3] Ingle Sud, 1989, Meningkatkan Produktivitas Melalui Daya Manusia, Pustaka Sinar Harapan, Jakarta.

[4] Ishikawa Kaoru Prof., 1990,Quality Control Circle at Work, PT Binaman Teknika Aksara, Jakarta.

[5] Buku Pedoman Astra Total Quality Control (ATQC).2000, PT Astra International, Jakarta.

[6] Gugus Kendali Mutu (GKM), 2007, Direktorat Jenderal Industri Kecil Menengah Departemen Perindustrian, Jakarta.

[7] Moen, Ronald; Norman, Clifford. "Evolution of the PDCA cycle" (PDF). westga.edu. Paper delivered to the Asian Network for Quality Conference in Tokyo on September 17, 2009.

[8] Dubickis, Mikus; Gaile-Sarkane, Elina (December 2017). "Transfer of know-how based on learning outcomes for development of open innovation". Journal of Open Innovation: Technology, Market, and Complexity. 3 (1): 4. doi:10.1186/s40852-017-0053-4

[9] Azwir, Hery H; Setyanto, Agus K. "AnalisisPenerapan Lean Manufacturing pada Penurunan Cacat Feed Roll Menggunakan Metode PDCA". Jurnal Rekayasa Sistem Industri, Vol. 6, No. 2, Oktober 2017. 